Article

\title{
Projection of Greenhouse Gas Emissions for the Road Transport Sector Based on Multivariate Regression and the Double Exponential Smoothing Model
}

\author{
Reham Alhindawi ${ }^{1, *}$, Yousef Abu Nahleh ${ }^{2, *}$, Arun Kumar ${ }^{1}$ and Nirajan Shiwakoti ${ }^{1}$ (D) \\ 1 School of Engineering, RMIT University, Melbourne, VIC 3000, Australia; arun.kumar2@rmit.edu.au (A.K.); \\ nirajan.shiwakoti@rmit.edu.au (N.S.) \\ 2 College of Engineering and Technology, American University of the Middle East, Kuwait \\ * Correspondence: rehamjalhindawi@gmail.com (R.A.); yousef.abunahleh@aum.edu.kw (Y.A.N.)
}

Received: 8 September 2020; Accepted: 28 October 2020; Published: 3 November 2020

check for updates

\begin{abstract}
The economic and health impacts resulting from the greenhouse effect is a major concern in many countries. The transportation sector is one of the major contributors to greenhouse gas (GHG) emissions worldwide. Almost 15 percent of the global GHG and over 20 percent of energy-related $\mathrm{CO}_{2}$ emissions are produced by the transportation sector. Quantifying GHG emissions from the road transport sector assists in assessing the existing vehicles' energy consumptions and in proposing technological interventions for enhancing vehicle efficiency and reducing energy-supply greenhouse gas intensity. This paper aims to develop a model for the projection of GHG emissions from the road transport sector. We consider the Vehicle-Kilometre by Mode (VKM) to Number of Transportation Vehicles (NTV) ratio for the six different modes of transportation. These modes include motorcycles, passenger cars, tractors, single-unit trucks, buses and light trucks data from the North American Transportation Statistics (NATS) online database over a period of 22 years. We use multivariate regression and double exponential approaches to model the projection of GHG emissions. The results indicate that the VKM to NTV ratio for the different transportation modes has a significant effect on GHG emissions, with the coefficient of determination adjusted $R^{2}$ and $R^{2}$ values of $89.46 \%$ and $91.8 \%$, respectively. This shows that VKM and NTV are the main factors influencing GHG emission growth. The developed model is used to examine various scenarios for introducing plug-in hybrid electric vehicles and battery electric vehicles in the future. If there will be a switch to battery electric vehicles, a $62.2 \%$ reduction in $\mathrm{CO}_{2}$ emissions would occur. The results of this paper will be useful in developing appropriate planning, policies, and strategies to reduce GHG emissions from the road transport sector.
\end{abstract}

Keywords: transport systems; greenhouse gas emissions; multivariate regression; double exponential smoothing; climate change

\section{Introduction}

The greenhouse effect is a major concern in many countries. This is due to the high degrees of GHGs emissions released into the atmosphere [1]. One of the contributors to GHG emissions is the emissions from the transportation sector. The growing number of cars and trucks has triggered an incredible rise in GHG emissions. In 2007, $23 \%$ of the worldwide GHG emissions came from the transportation sector with $73 \%$ of it coming from the road transportation sector [2].

The transport services sector has witnessed a rapid rise in the past four decades, with the continuous increase in carbon dioxide $\mathrm{CO}_{2}$ emissions from this sector becoming an important worldwide issue. According to the International Transport Forum [3], $\mathrm{CO}_{2}$ emissions from the road transport sector 
represent $30 \%$ of the overall carbon dioxide emissions from fossil fuel burning. The transport sector accounts for around $15 \%$ of total GHG emissions. Moreover, there was a $45 \%$ increase in global $\mathrm{CO}_{2}$ emissions from 1990 to 2007. This continuing rise in $\mathrm{CO}_{2}$ emissions from road transport is an immense challenge for road authorities and governments [3].

Since 2008, GHG emissions from the transport sector have begun to diminish. Despite this trend, in 2012, the transport sector's emissions were still 20.5\% above 1990 levels and needed to decrease by 67 percent by 2050 to meet the 2011 Transport White Paper target of 60 percent of 1990 emissions [4].

Currently, globalization, GHG outflows, energy concerns, vehicle innovations, and development of enhanced statistical modeling techniques provide an opportunity to revisit total vehicle miles travelled, energy utilization and GHG emissions predictions for passenger transport [5].

Most recently, there has been growing concern about the implications of GHG emissions from the transportation sectors. As a result, strategies and policy measures are being developed to reduce GHG emissions around the world [6].

Several options are put forward to forecast GHG emissions. However, the validity of these methods has been affected by the non-consideration of non-linear variables in the model. Also, the quantity of emissions generated from road traffic is dynamic and uncertain [7]. Due to this complex and uncertain interaction of variables contributing to GHG emissions, the inclusion of non-linear variables is important for the forecast of GHG emissions to improve the model's predictions.

Modelling environmental data is a complex task because of the underlying correlation between multiple variables. Therefore, studies are being conducted to improve the forecast for GHG emissions. In the literature, several methods have been proposed to forecast GHG emissions. Usually, historical data are important for the development of those models. The majority of the forecasting methods aim at improving the accuracy of the results [1].

The latest research has been typically inclined to focus on the influences of GHG emissions towards the environment [8]. Most of the studies attempted to propose policies which can be implemented to reduce GHG emissions. These policies usually target the road sector, consisting of activities such as fiscal measures that include automotive and fuel taxes. Other policies involve seeking voluntary consensus with vehicle companies so that they can work towards a reduction of energy consumption by cars and trucks. Likewise, policy on targeted campaigns that encourage people to purchase fuel-efficient vehicles has been also suggested. Further, the introduction of vehicle usage charges for the reduction of $\mathrm{CO}_{2}$ emissions by encouraging efficient use of the vehicles has been proposed. The impacts of several other factors which include vehicle energy consumption, fleet demand and load can be forecasted and evaluated through quantitative modelling [9]. Most of these models make use of a "bottom-up" or a "top-down" method, which lead to similar results, measured as cost-efficiency per ton of $\mathrm{CO}_{2}$ reduced [9]. The bottom-up modelling tools are developed from micro-level data (for example, a fuel/energy efficiency model developed from disaggregated information of the vehicle stock). In contrast, top-down models are based on equations capturing historical relationships between macroeconomic parameters (for example, a top-down fuel/energy use model would be developed using macroeconomic equations) that estimate the demand for fuels or energy consumption from roads transport [10]. Having said that, modelling tools that forecast $\mathrm{CO}_{2}$ emissions have many constraints. In particular, the unavailability of detailed data is a big constraint (e.g., fuel/energy consumption per vehicle, average annual distance travelled). Likewise, the use of many equations to satisfy various assumptions has also been a challenge. Moreover, such equations are sometimes difficult to use effectively due to the rigidity of the methodology and assumptions [9].

\section{Objective and Scope of Study}

This paper aims to develop a multivariate linear regression and double exponential smoothing model for the projection of GHG emissions from the road transport sector in the North America region. We used the ratio between the number of transportation vehicles (NTV) and vehicle kilometers travelled (VKT). The ratio considers the six modes of transport: light trucks, tractors, motorcycles, 
passenger cars, buses and single-unit trucks. The proposed approach will enable researchers and planners to calculate the GHG generated from the road sector and will assist in developing appropriate measures towards travel demand management and introducing clean vehicle technologies. A review of the related literature reveals that there is a lack of study that has examined the GHG emissions from the road transport sector considering the VKT and NTV ratio for different modes of road transport.

The structure of the paper is as follows. Part 2 provides a literature review, followed by the research methodology in Part 3. Part 4 presents the results obtained from a multivariate linear regression model and double exponential smoothing models to predict GHG emissions. The final part presents recommendations for future research and conclusions.

\section{Literature Review}

Emission variables in the transportation field have been considered in several studies in the literature. These variables are generally influenced by the transport routes, distance travelled, age and size of the vehicles [11].

In the literature, various approaches have been proposed by the researchers to forecast GHG emissions. These approaches can be classified into five main categories: time series study, decomposition analysis, regression analysis, bottom-up method and system optimization tool.

Saboori et al. [12] applied time series analysis to examine the nexus between the emissions of $\mathrm{CO}_{2}$ from the transport sector and the economic growth of OECD countries. Forecasting the $\mathrm{CO}_{2}$ emission trends from the vehicles, vehicular energy intake and population to improve management of $\mathrm{CO}_{2}$ emissions have been a recent focus in Taiwan [13]. Meyer et al. [14], present a demand analysis of passenger vehicles in 11 regions and the associated $\mathrm{CO}_{2}$ emissions.

Likewise, Tokunaga and Konan [15] and Konur [16] used panel data to provide estimations of $\mathrm{CO}_{2}$ from the transportation sector. Tolón-Becerra et al. [17] focus on the emission reduction targets of EU countries. A study found a relationship of a co-combination of fuel price (FP) and pay per capita on transport fuel consumption (FC) [18]. Also, the relationship between $\mathrm{CO}_{2}$ discharges and vitality utilization have been highlighted in the literature [18-22]. Begum et al. [23] examined the implications of GDP, FC and population on the emissions of $\mathrm{CO}_{2}$. Several recommendations were put forward by Ivy-Yap and Bekhet [24] that have the potential to reduce $\mathrm{CO}_{2}$ emissions such as the use of low-carbon technologies. Additionally, Talbi [25] used the Vector Autoregressive (VAR) model to investigate the impact of energy consumption, economic growth, urbanization and fuel rate on $\mathrm{CO}_{2}$ emissions. The influencing factors for the changes in $\mathrm{CO}_{2}$ emissions from the transportation sector were also further analyzed. Magazzino et al. [26] used the time series analysis and a Machine Learning approach to develop a relationship between municipal waste generation, GDP, and GHG emissions.

The growing $\mathrm{CO}_{2}$ emissions can influence changes in modal shift, fuel mix, economic growth, transport energy intensity, and emission coefficients. Using a decomposition method, Timilsina and Shrestha [27] found that transportation energy intensity and economic growth are the major variables for $\mathrm{CO}_{2}$ emissions. Furthermore, economic growth roles in the contribution of $\mathrm{CO}_{2}$ emissions in ASEAN-5 and EU27 economies have been established [28,29].

Lakshmanan and Han [30] applied decomposition analysis and found that population and GDP were the main causes of $\mathrm{CO}_{2}$ emissions in the transport sector. Further, Logarithmic Mean Division Index (LMDI) and Kaya Identity approaches were used by $\mathrm{Li}$ [31] to estimate the $\mathrm{CO}_{2}$ emissions of urban freight, identify key parameters of emissions change, and to use those parameters to predict $\mathrm{CO}_{2}$ emissions from the transport sector. Likewise, a multivariate generalized Fisher index (GFI) decomposition model based on the extension of Kaya Identity was built by Fan and Lei [32] to estimate the influence of the energy structure, energy intensity, per unit traffic turnover, transportation intensity, economic growth and population size on carbon emissions in the transportation sector of Beijing.

By using regression analysis, Sadorsky [33] investigated the connection involving GDP, salary, urbanization, and vitality demand and discovered that $\mathrm{CO}_{2}$ emissions could be reduced by shifting to renewable energies. While high $\mathrm{CO}_{2}$ emissions are accumulated in dense road network (e.g., cities 
with high population density), low $\mathrm{CO}_{2}$ emissions are distributed in low population density areas with scattered road networks (e.g., rural areas) [34]. Alhindawi et al $[35,36]$ identified the main factors of GHG emissions for the roads sector using the ratio between vehicle-kilometers and number of transportation vehicles for six transportation modes. Likewise, $\mathrm{Xu}$ et al. [37] found the influence of vitality structure, population, vitality intensity and GDP on $\mathrm{CO}_{2}$ emissions. GDP was found out to be the main factor for $\mathrm{CO}_{2}$ emissions, followed by the vitality structure and population. Friedrich and Trois [38], through a combination of regression analysis and life cycle assessment approach, estimated the GHG emissions for solid waste management. They used specific emission factors for various waste management processes and included upstream, downstream and operational GHG emissions. To study the relationship between road transport energy consumption, transport $\mathrm{CO}_{2}$ emissions, and economic activity in Saudi Arabia, the autoregressive distributed lag (ARDL) approach was used by Alshehry and Belloumi [39]. The impact of GDP, energy intensity, carbon intensity, and total population on carbon dioxide emissions in China's transport industry was investigated by Lin and Benjamin [40]. They used the quantile regression analysis and found that rather than urbanization, it is the GDP, energy intensity, and carbon intensity that have a greater impact on carbon emissions. Danish et al. [41] applied autoregressive distributive lag (ARDL) and vector error correction model (VECM) to examine the relationship between transport energy consumption, economic growth and $\mathrm{CO}_{2}$ emissions to account for the effect of Foreign Direct Investment (FDI) and urbanization. The results also showed a significant impact of transport energy consumption on $\mathrm{CO}_{2}$ emissions from the transportation sector. Van der Zwaan et al. [42] conducted a study on $\mathrm{CO}_{2}$ emissions of transport divisions and the decarbonization strategies in Europe. In Italy, strategies have been developed through COPERT III methodology in the analysis of road transport emissions [43]. This method was also used to study vehicles emissions in urban areas [44-46]. A multi-model, a time series and bottom-up approaches, were used by Paladugula et al. [47] to estimate the energy consumption and emissions from India's transportation sector. In the literature, many optimization models have been proposed to forecast $\mathrm{CO}_{2}$ emissions and recommend solutions to reduce $\mathrm{CO}_{2}$ emissions. Several studies have utilized linear programming models to investigate the benefits of energy choices that can assist in the reduction of $\mathrm{CO}_{2}$ emissions by industries [48-50]. Furthermore, a mixed-integer model has been recommended by Hashim et al. [51] that further sheds light on the effects of fuel switching and balancing on power generation. Their study shows that shift to fuel efficiency is one of the most effective choices to reduce $\mathrm{CO}_{2}$ emissions. This was supported by other research that used mixed-integer linear programming for waste to vitality to ensure costs reductions were related to $\mathrm{CO}_{2}$ emissions and electricity generation [52]. Güzel and Alp [53] examined the impacts of the transport sector on climate change in Istanbul.

Generally, after a period of time, the road transport sector's GHG outflows demonstrate a pattern [54]. Therefore, through the use of statistical forecasting techniques, researchers and planners can anticipate future outflows. Brown [55] and Brown and Meyer [56] pioneered the double exponential smoothing (DES) method to predict the variety of a noise, and a trend for forecasting. This technique has since been advanced by Goodman [57], Gardner [58] and Gijbels et al. [59] for various applications. For example, Goodman [57] made a remaining examination to upgrade the appraisal of the exactness of DES models, while Gardner [58] developed a general exponential smoothing technique that considers regularity. Likewise, Gijbels, Pope and Wand [59] added knowledge to the existing exponential smoothing hypothesis by using a DES model inside a nonparametric regression structure.

There are various studies which have demonstrated the use of DES models in different fields which include ecological contamination. For instance, a DES model was used in South Korea to anticipate the arrangement of ozone and how it contributes to air pollution [60]. In England, a DES model was used to gauge power request and help in minimizing the regular effects which are associated with the utilization of power [61]. In China, a DES model was used in the creation of an indicator for the indication of defilement of stream water [62]. Furthermore, a DES model was used in the assessment of $\mathrm{CO}_{2}$ contamination by urban traffic roads [63]. In the US, a DES model was used to look to assess the diminishing pattern of $\mathrm{CO}_{2}$ emissions as well as performing forecasts [54]. 
This section provided a comprehensive review of the tools, methods and factors used for the forecast of GHG emissions. Tables 1 and 2 provide a summary of the methodology adopted in the existing literature to predict GHG emissions in various industry sectors. Table 1 shows the pros and cons of different forecasting approaches. Table 2 shows the summary of models used in the transport sector along with the regions where those studies have been conducted. As can be seen, linear regression analysis and DES models have been less examined, particularly for predicting GHG emissions from the road transportation sector. Therefore, by considering linear regression analysis and DES models, the present study will contribute towards the modelling of GHG emissions estimation and thereby identify critical factors that impact GHG emissions from the road transport sector.

Table 1. Comparison of Advantages and Disadvantages of Different Forecasting Approaches (Source: Authors' synthesis).

\begin{tabular}{|c|c|c|}
\hline Techniques & Pros & Cons \\
\hline $\begin{array}{l}\text { Decomposition } \\
\text { models }\end{array}$ & - It is simple to comprehend & $\begin{array}{l}\text { A cycle element is required to be input by the } \\
\text { forecaster as it is not estimated through the tool. }\end{array}$ \\
\hline $\begin{array}{c}\text { System } \\
\text { optimization }\end{array}$ & $\begin{array}{c}\text { Can be easy to use } \\
\text { - Have a small number of variables to modify } \\
\text { Capable to function parallel calculation } \\
\text { Is usually effective }\end{array}$ & $\begin{array}{c}\text { - Can be difficult to define initial } \\
\text { design parameters } \\
\text { - Cannot work out the problems of scattering }\end{array}$ \\
\hline Regression analysis & - Simple to apply and understand & The calculation process may be cumbersome. \\
\hline $\begin{array}{l}\text { Double exponential } \\
\text { smoothing }\end{array}$ & $\begin{array}{l}\text { It is easy to learn and implement. } \\
\text { The accuracy level for forecasts is usually high } \\
\text { It gives more significance to recent } \\
\text { observations and weights them accordingly. } \\
\text { The spikes in the data aren't quite as } \\
\text { detrimental to the forecast as previous methods. }\end{array}$ & $\begin{array}{l}\text { It limits our ability to forecast demand } \\
\text { using seasonality. }\end{array}$ \\
\hline
\end{tabular}


Table 2. A Summary of Literature Outlining the Methodology Adopted for GHG Emissions from the Transport Sector (Source: Authors' synthesis).

\begin{tabular}{|c|c|c|c|c|}
\hline Author/Year & Sector & Country & Time Period & Methodology/Approach \\
\hline Lakshmanan and Han (1997) & Transport & USA & 1970-1991 & Decomposition \\
\hline El-Fadel et al. (1999) & Transport & Lebanon & forecast 1997-2020 & $\begin{array}{l}\text { Automobile Emission Inventory MVEI, Intergovernmental Panel at } \\
\text { Climate Modify IPCC, Motor Vehicle Emission Selection MVEI, } \\
\text { Intergovernmental Board on Climate Improve IPCC }\end{array}$ \\
\hline Singh et al. (2008) & Transport & India & 1980-2000 & Time series \\
\hline Kamarudin et al. (2009) & Transport & Malaysia & - & Linear programming \\
\hline Timilsina and Shrestha (2009) & Transport & Asian countries & 1980-2005 & Decomposition \\
\hline Sultan $(2010)$ & Transport & Mauritus & - & Time series, Autoregressive distributed lag (ARDL) approach \\
\hline Borjesson and Ahlgren (2012) & Transport & Sweden & 1995-2051 & Linear programming \\
\hline Shu and Lam (2011) & Transport & Louisiana & 2002-2006 & Multiple regression model \\
\hline Wang et al. (2011) & Transport & China & 1995-2007 & Decomposition \\
\hline Chandran and Tang (2013) & Transport & ASEAN & 1971-2008 & $\begin{array}{l}\text { Johansen co-integration, Granger causality, Vector error correction } \\
\text { model VECM }\end{array}$ \\
\hline Ackah and Adu (2014) & Transport & Ghana & $1971-2010$ & Time series \\
\hline Choi et al. (2014) & Transport & USA & 1960-2011 & Double exponential smoothing \\
\hline Xu and Lin (2015) & Transport & China & 2000-2012 & Regression analysis \\
\hline Mustapa and Bekhet (2015) & Transport & Malaysia & 1990-2013 & Multiple regression model \\
\hline Alhindawi et al. (2016) & Transport & USA & 1990-2012 & Multiple regression model \\
\hline Fan, F., \& Lei, Y. (2016) & Transport & Beijing & 1995-2012 & Decomposition \\
\hline Alshehry et al. (2017) & Transport & Saudi Arabia & 1971-2011 & Granger causality, Autoregressive distributed lag (ARDL) approach \\
\hline Talbi, B. (2017) & Transport & Tunisia & 1980-2014 & Time series, Vector autoregressive (VAR) model \\
\hline Lin, B., \& Benjamin, N. I. (2017) & Transport & China & 1980-2010 & Regression analysis \\
\hline Danish et al. (2018) & Transport & Pakistan & 1990-2015 & (ARDL) approach and VECM model \\
\hline Paladugula, A. L. et al. (2018) & Transport & India & up to 2050 & Multi-model approach \\
\hline Stephane el al. (2019) & Transport & India & $2015-2050$ & Bottom-Up approach \\
\hline Alhindawi et al. (2019) & Transport & USA & 1990-2012 & Adaptive Neuro-Fuzzy Technique \\
\hline Güzel and Alp (2020) & Transport & Istanbul & $2016-2050$ & Linear programming model \\
\hline
\end{tabular}




\section{Model Development}

Although there are various methods in the literature to forecast GHG emissions, there are differences in their scope and assumptions as they depend on data gathered from various countries. This may lead to variations in the results obtained. Although Alhindawi et al. [35] used a Multivariate Regression Model to forecast GHG emissions, its performance has not been compared with other similar methods such as the double exponential model. Further, the applicability of such forecasting tool in scenario analysis was not examined in Alhindawi et al. [35]. Therefore, in this study, the emphasis has been on a general robust approach which can be used in analysing and identifying various factors that influence the GHG emissions and developing a forecast of GHG emissions from the road transport sector. Further, we conduct scenario analysis by examining the effect of introducing plug-in hybrid electric vehicles and battery electric vehicles in the future in terms of greenhouse gas emissions reduction. The study process is comprised of two sections:

1. A multivariate linear regression analysis (MRA).

2. A double exponential smoothing model (DES).

This model is constructed based on both NTV and VKT historical data which spans over a period of 20 years from the North America region.

To develop a good MRA model which can be used in GHG emissions forecasting, each variable needs to have a predicted value. In this paper, a forecasting tool which was based on the DES technique was used in generating these predicted values. The DES method has been highly recommended in the handling of historical data by Sullivan and Claycombe [64], Hyndman et al. [65] and is, therefore, a suitable tool in this study.

\subsection{Variables}

\subsubsection{Vehicle Kilometres by Mode (VKM)}

The efficiency of a vehicle fleet in terms of its activity or the volume of traffic is expressed as vehicle kilometers by mode (VKM). In transport planning, VKM is commonly used for estimating vehicle emissions. Also, VKM can inform decision making and policies such as infrastructure investment decisions and road safety policy. Therefore, accurate VKM estimations are critical [66].

\subsubsection{Number of Transportation Vehicles (NTV)}

This study includes various categories of vehicles including light trucks, tractors, combination trucks as well as passenger cars [66]. An increase of NTV will result in higher GHG emissions.

\subsection{Data Sources}

The researchers collected the historical data used in this study on Vehicle-kilometers by Mode (VKM) and Number of Transportation Vehicle (NTV) of road transport, 1990-2012, from the official data source of the North American Transportation Statistics (NATS) online database [67]. These data are utilized to build the regression model and to forecast the GHG emissions using the estimation from a double exponential smoothing model. Table 3 shows the complete set of the data used in this study. 
Table 3. Data Set for the Model (Ratio (Vehicle-Kilometers Travelled by Mode (Millions of Vehicle-Kilometers)/Number of Transportation Vehicles (Equipment)).

\begin{tabular}{|c|c|c|c|c|c|c|c|}
\hline \multirow{2}{*}{ Year * } & \multirow{2}{*}{$\begin{array}{c}\text { GHG } \\
\text { Emissions }\end{array}$} & \multicolumn{6}{|c|}{$\begin{array}{c}\text { Ratio (Vehicle-Kilometres by Mode (Millions of Vehicle-Kilometres)/Number of } \\
\text { Transportation Vehicles/Equipment) }\end{array}$} \\
\hline & & $\begin{array}{l}\text { Passenger } \\
\text { Cars }\end{array}$ & Motorcycles & Light Trucks & Bus & $\begin{array}{l}\text { Single-Unit } \\
\text { Trucks }\end{array}$ & Tractor \\
\hline 1990 & $1,235,100$ & $16,951.2$ & 3611.02 & $19,154.65$ & $14,697.27$ & $18,615.41$ & $88,845.13$ \\
\hline 1995 & $1,352,700$ & $18,029.19$ & 4045.73 & $19,340.74$ & $15,072.14$ & $20,087.7$ & $109,567.97$ \\
\hline 1996 & $1,388,200$ & $18,234.27$ & 4123.62 & $19,007.95$ & $15,201.91$ & $19,580.98$ & $109,556.01$ \\
\hline 1997 & $1,416,900$ & $18,637.02$ & 4240.05 & $19,496.62$ & $15,785.29$ & $20,337.56$ & $112,012.62$ \\
\hline 1998 & $1,461,200$ & $18,915.58$ & 4265.81 & $19,589.92$ & $15,760.13$ & $19,088.13$ & $103,424.3$ \\
\hline 1999 & $1,511,800$ & $19,068.06$ & 4101.93 & $19,242.62$ & $16,920.13$ & $19,633.12$ & $105,025.63$ \\
\hline 2000 & $1,521,500$ & $19,273.95$ & 3876.61 & $18,783.83$ & $16,371.25$ & $19,145.87$ & $103,640.19$ \\
\hline 2001 & $1,527,400$ & $19,028.74$ & 3161.7 & $18,019.17$ & $15,179.82$ & $20,427.1$ & $102,001.97$ \\
\hline 2002 & $1,562,500$ & $19,636.86$ & 3071.85 & $18,287.93$ & $14,481.08$ & $21,607.19$ & $98,071.69$ \\
\hline 2003 & $1,571,300$ & $19,833.21$ & 2869.81 & $18,163.64$ & $14,054.47$ & $21,394.12$ & $118,171.31$ \\
\hline 2004 & $1,604,400$ & 20,052 & 2824.23 & $17,998.3$ & $13,762.55$ & $20,489.92$ & $113,972.05$ \\
\hline 2005 & $1,612,100$ & $20,132.35$ & 2701.72 & $17,573.58$ & $13,919.78$ & $19,753.29$ & $111,076.55$ \\
\hline 2006 & $1,609,800$ & $20,093.44$ & 2903.45 & $17,574.81$ & $13,281.68$ & $19,445.7$ & $105,453.36$ \\
\hline 2007 & $1,614,100$ & $17,236.04$ & 4823.72 & $24,091.42$ & $27,996.16$ & $23,788.94$ & $112,486.14$ \\
\hline 2008 & $1,540,100$ & $16,560.69$ & 4319.92 & $24,552.89$ & $28,287.41$ & $24,632.22$ & $114,434.35$ \\
\hline 2009 & $1,500,100$ & $16,704.39$ & 4221.33 & $24,521.05$ & $27,443.22$ & $23,142.86$ & $103,211.24$ \\
\hline 2010 & $1,509,000$ & $17,144.27$ & 3711.09 & $24,895.69$ & $26,239.55$ & $21,684.42$ & $110,940.84$ \\
\hline 2011 & $1,489,900$ & $17,089.15$ & 3575.54 & $23,499.82$ & $33,315.12$ & $21,314.6$ & $107,497.11$ \\
\hline 2012 & $1,487,100$ & $18,128.56$ & 4053.84 & $19,121.97$ & $31,059.15$ & $20,623.94$ & $106,475.9$ \\
\hline
\end{tabular}

\subsection{Data Limitations}

NTV data are based on information collected by the Department of Transportation in the U.S. The vehicle categories include passenger cars, light trucks and combination truck tractors. Data for light trucks include pick-up trucks, vans and sport utility vehicles. Combination truck tractors were categorized under "tractors". Passenger cars include taxis. Buses include local motor buses [67].

Passenger cars, light trucks and motorcycles are included in the VKM data. In 1997, the Department of Transportation in the U.S. updated the VKM data on the highway mode for several years. The main change included the relocation of some vehicles from the passenger car category to the light truck category [67].

The discontinuities in the data set as stated above may lead to some errors in the regression model's estimation. However, when a detailed good data set is available, the generality of the proposed method and the results obtained in this study could be further examined in the future.

\subsection{Regression Analysis and Double Exponential Model}

Regression analysis has been generally used in the examination of multifaceted information which is achieved through the creation of mathematical statements that shows how a response is related to a set of independent variables or predictors. GHG emissions are used as the response variable in this model. The VKM to NTV ratios for the six transportation modes are used as the causal variables in this study. These modes are depicted as follows; Light Trucks (LT), Passengers Cars (PC), Tractors (T), Motorcycles (C), Single Unit Truck (SUT) and Buses (B). It should be noted that there could be other several causal variables, but due to data unavailability, only the above parameters were considered in this study. Additionally, aggregated data analysis has been conducted by the researchers rather than carrying out a disaggregation of data into multiple modules of transport. In order to avoid the average squared residual which is associated with a recent one-step-ahead during forecasting, exponential smoothing is done by specifying a smoothing factor. According to Hyndman et al. [65] and Sullivan 
and Claycombe [66], the equation and formula which are used in double exponential forecasting are as shown below(Equations (1)-(6)):

$$
F_{t+m}=a_{t}+b_{t} m
$$

where:

- $\quad F_{t+m}$ is the forecast's representation after the performance of $m$ of periods.

- $a_{t}$ depicts the forecasted intercept while $b_{t}$ is the forecasted slope.

- $\quad$ The intercept $a_{t}$ and the slope $b_{t}$ are approximated as shown in Equations (2)-(4):

$$
\begin{gathered}
a_{t}=2 S^{\prime}{ }_{t}-S^{\prime \prime}{ }_{t} \\
b_{t}=\frac{\alpha}{1-\alpha}\left(S^{\prime}{ }_{t}-S^{\prime \prime}{ }_{t}\right) \\
0 \leq \alpha<1
\end{gathered}
$$

$\alpha$ is the smoothing constant which is used when weighing the past and current observations and it lies in this range; $0<\alpha<1$. When the value of $\alpha$ is less than one it is considered to have less of a smoothing effect, and this gives a greater weight the latest changes that have taken place in the data. When the value of $\alpha$ is closer to 0 it is concluded that it has a greater smoothing effect hence it becomes less responsive to changes that have been conducted recently. The selection has no specific formal procedure which is correct for DES and single values for time $X_{t}$, and t respectively. The values $S^{\prime}{ }_{t}$ and $S^{\prime \prime}{ }_{t}$ are computed using the formula shown below in Equations (5) and (6).

$$
\begin{gathered}
S^{\prime}{ }_{t}=\alpha X_{t}+(1-\alpha) S^{\prime}{ }_{t-1} \\
S^{\prime \prime}{ }_{t}=\alpha S^{\prime}{ }_{t}+(1-\alpha) S^{\prime \prime}{ }_{t-1}
\end{gathered}
$$

On the other hand, when $\alpha$ is higher it means that more weight has been given to the current observations which are most recent. Before one runs a model, one needs to choose $\alpha$ first. This is followed by a computation of forecasts which is achieved by the use of a variety of $\alpha$ values. The value which results into a small mean squared error during the calculations is concluded to have shown the expected future growth. Besides the selection of $\alpha$ value approximates, $S_{t-1}^{\prime}$ and $S^{\prime \prime}{ }_{t-1}$ values should be assumed with the values of $t=1$ since there are no values that exist at that period. This is achieved after consideration of the equality of both values when compared with the original set of historical data $[64,65]$.

\section{Results and Discussions}

This section brings out a presentation and discussion of the main results which have been obtained after carrying out an analysis of a multivariate regression of the GHG emissions model.

\subsection{Regression Analysis Results}

Minitab software was used in the analysis of this regression. It was also used together with the application of an Analysis of Variance (ANOVA) test to check the significance of the multivariate linear regression model.

Results which were obtained after conducting this analysis have been presented well in Table 4 below. All coefficients together with their expected signs have been well indicated. The negative sign shows that the predicted value of the dependent variable will be a value which is less than zero with a condition where the predictor values used are set to 0 . This should always be the expectation in cases where the dependent variable has a negative mean value. It is worth noting that it is the overall and general relationship among variables which forms one of the most significant parts of the regression model. 
This section utilizes some of the aforementioned six modes of transportation which are abbreviated as passenger cars (PC), light trucks (LT), single unit trucks (SUT), buses (B), motorcycles (M) and tractors (T). After standardization of all coefficients, PC has been established to have the largest absolute value and then it is followed by LT, B and SUT respectively. Hence, PC is established as the most important variable in this study. To establish the importance of the variable in a given model, an estimation of the p-value is carried out. In this study, the p-values have been established and presented in the table as shown below. Consideration was given to the variables that had a p-value of less than 0.05. The output below shows predictor values for LT, B, PC and SUT since their $\mathrm{p}$-values fall within the range of $0.0-0.05$. The $p$-values for the Tractors and Motorcycles were 0.317 and 0.693 respectively. Hence, they were excluded from the model.

Table 4. Regression Outputs for the GHG Emissions.

\begin{tabular}{cccc}
\hline Variables & Coefficient & $\boldsymbol{p}$-Value & Variation Inflation Factors (VIF) \\
\hline Constant & $-1,883,486$ & 0.000 & \\
Passenger cars (PC) & 121.5 & 0.000 & 4.11 \\
Light trucks (LT) & 23.99 & 0.009 & 3.60 \\
Bus (B) & 5.69 & 0.011 & 3.22 \\
Single-unit trucks (SUT) & 26.34 & 0.004 & 2.70 \\
\hline
\end{tabular}

Note: *: $R^{2}=90.8 \%$, Adjusted $R^{2}=89.46 \%$, Predicted $R^{2}=84.88 \%$. Where, $R^{2}$ is the percentage of the response variable variation which shows how close the data fits the regression line, and adjusted $R^{2}$ compares the explanatory power of regression models that contain different numbers of predictors. ${ }^{*}$ Coefficients are important at the 0.05 level.

\subsection{Model Adequacy Check}

To ensure verification of the multivariate linear regression model, it is important to ensure that adequacy of the model has been checked. Regression analysis involves the use of an ANOVA tool that tests the importance and validity of the model. This is carried out based on some few assumptions. These include the residuals having an even distribution and a constant variance. These assumptions are validated using a graph which analyzes the residuals. To determine whether a small set of data are part of a given normal distribution, a plot showing normal probability is made. Since the straight line represents data points, it is concluded that the distribution is normal. This is well depicted in Figure 1a. The assumptions are checked further by plotting a residual vs fitted values as shown in Figure $1 \mathrm{~b}$. According to these plots, a constant variance has been associated with errors. This has led to the dispersion of the residuals being around zero. For instance, an increase or decrease of residuals in a pattern with the fitted values leads to errors which do not have a constant variance. This plot has points which seem to have a random dispersion around zero and this brings forward an idea suggesting the error has a mean of 0 which is reasonable. The fitted values do not appear to increase or decrease as a result of the vertical width of the scatter plot. Hence, the variance of the error is assumed to be constant [68]. Therefore, this analysis demonstrates satisfactory results which fall within the horizontal band. Secondly, in this model, there was no detection of influence or leverage points. Thirdly, multicollinearity was also not detected in this model. When large Variation Inflation Factors (VIFs), usually larger than 10, are detected, this means that there was a poor estimation of the regression coefficients. This is normally caused by near-linear and multicollinearity dependencies among the regression variables which leads to outcomes which are misleading. In this study, variables which have VIF that is less than 10 has been demonstrated in Table 4. These results can be translated to indicate the non-existence of multicollinearity in this model. Fourthly, the model points represent the behavior of its data adequately as the coefficient of multiple determinations $\left(R^{2}\right)$, the adjusted $R^{2}$ and the predicted $\mathrm{R}^{2}$ statistics are $91.8 \%, 89.46 \%$, and $84.88 \%$ respectively.

Finally, the contribution of each vehicle category towards emissions of GHG is depicted by the last model (Equation (7)). Based on tests conducted previously, it can be concluded that the proposed model represents data accurately and has no violations towards the main assumptions. The equation for this model is as shown below in Equation (7). 
GHG Emissions $=-1,883,486+121.5$ Passenger cars +23.99 Light trucks +5.69 Bus + 26.3 Single - unit trucks

For example:

$$
\begin{gathered}
\text { GHG Emissions }(1990)=-1,883,486+(121.5 \times 16,951.2)+(23.99 \times 19,154.7) \\
+(5.69 \times 14,697.27)+(26.34 \times 18,615.41)=1,209,563
\end{gathered}
$$

The Error $\%(1990)=\frac{\text { Predicted value }- \text { Actual value }}{\text { Actual value }} \times 100 \%=\frac{1,209,563-1,235,102}{1,235,102} \times 100 \%=2.06 \%$

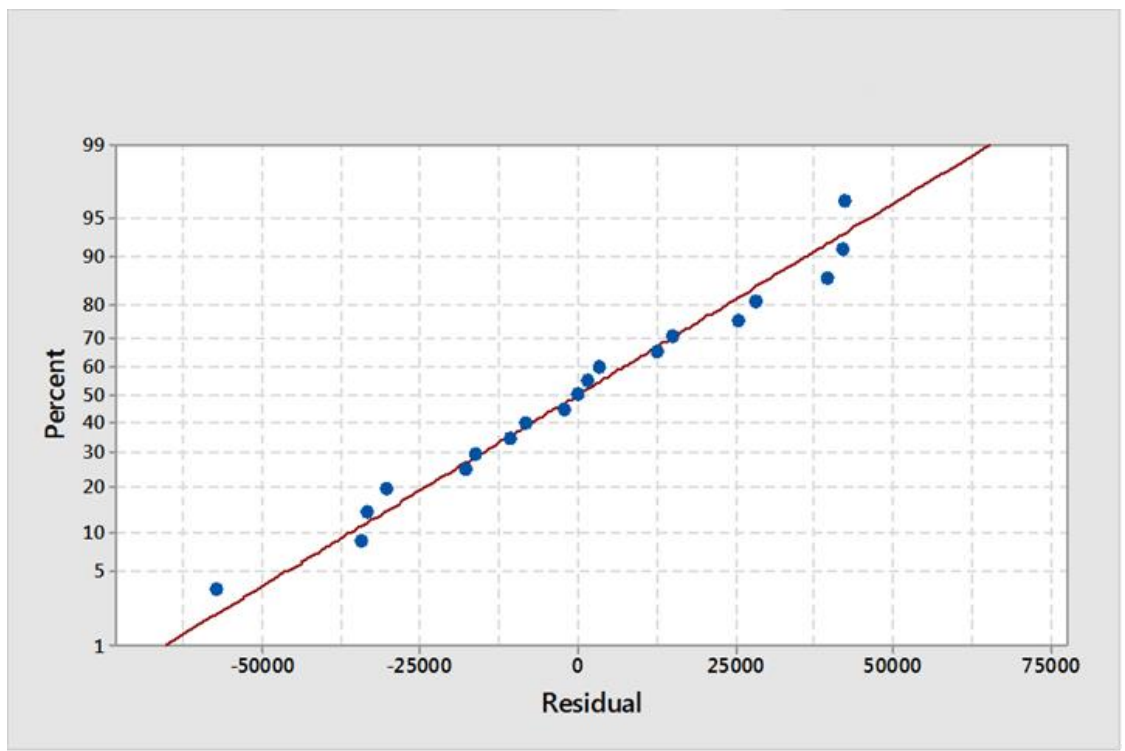

(a)

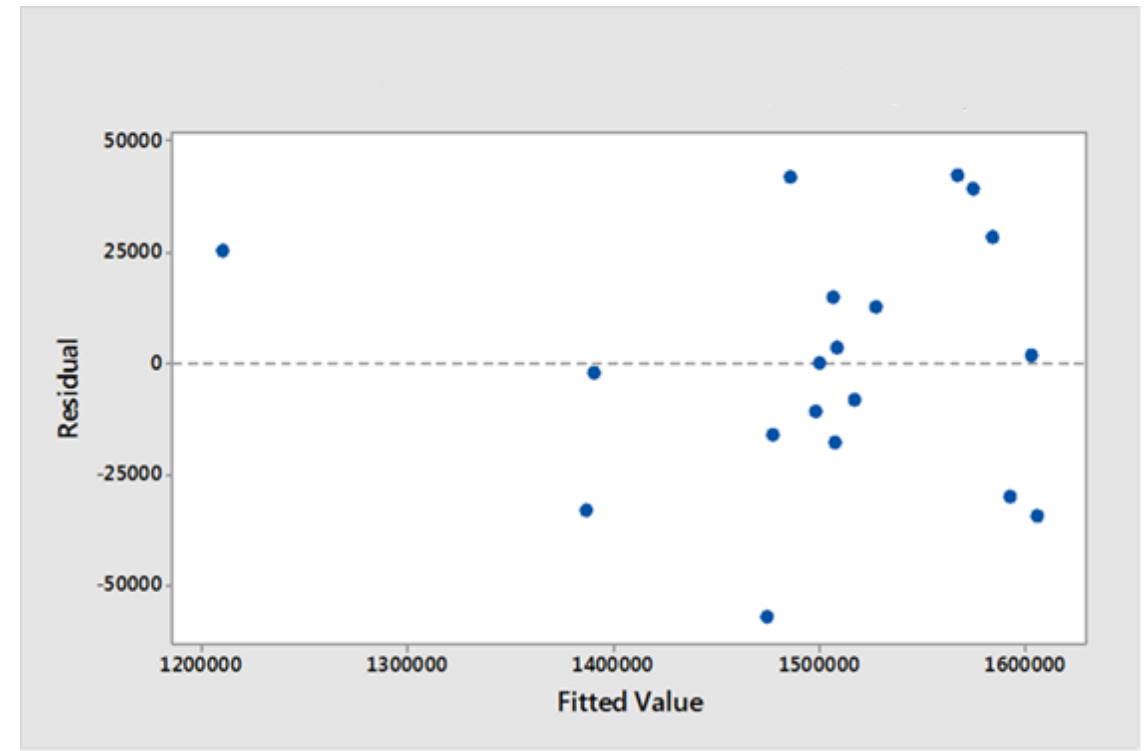

(b)

Figure 1. (a) Normal Probability Plot and (b) Residual versus Fitted Values, for the GHG Emissions Model. 
By application of Equation (7), there has been calculation of percentage error in order to draw a comparison between GHG real value and expected value. This has given a result value of $1.48 \%$ percentage error (Table 5).

Table 5. Error Calculation.

\begin{tabular}{cccc}
\hline \multirow{2}{*}{ Year } & \multicolumn{2}{c}{ Greenhouse Gas Emissions } & \multirow{2}{*}{ Error\% } \\
\cline { 2 - 3 } & Actual & Predicted & \\
\hline 1990 & $1,235,100$ & $1,209,562$ & 2.07 \\
1995 & $1,352,700$ & $1,385,915$ & 2.46 \\
1996 & $1,388,200$ & $1,390,240$ & 0.15 \\
1997 & $1,416,900$ & $1,474,145$ & 4.04 \\
1998 & $1,461,200$ & $1,477,176$ & 1.09 \\
1999 & $1,511,800$ & $1,508,326$ & 0.23 \\
2000 & $1,521,500$ & $1,506,378$ & 0.99 \\
2001 & $1,527,400$ & $1,485,209$ & 2.76 \\
2002 & $1,562,500$ & $1,592,651$ & 1.93 \\
2003 & $1,571,300$ & $1,605,486$ & 2.18 \\
2004 & $1,604,400$ & $1,602,625$ & 0.11 \\
2005 & $1,612,100$ & $1,583,690$ & 1.76 \\
2006 & $1,609,800$ & $1,567,259$ & 2.64 \\
2007 & $1,614,100$ & $1,574,545$ & 2.45 \\
2008 & $1,540,100$ & $1,527,430$ & 0.82 \\
2009 & $1,500,100$ & $1,500,092$ & 0.00 \\
2010 & $1,509,000$ & $1,517,261$ & 0.55 \\
2011 & $1,489,900$ & $1,507,596$ & 1.19 \\
2012 & $1,487,100$ & $1,497,831$ & 0.72 \\
& & & 1.48 \\
\hline
\end{tabular}

Application of the DES model, which was described in Equation (1), can be used to calculate GHG emissions forecasted variables over a long period of time which could even be from 1990-2060. This is made possible by the use of smoothing constants $\left(\alpha^{\prime}\right.$ s) as depicted in Table 6. By using a predicted period of 1990 to 2012, the resulting variables have been used in the calculation of percentage error of projection, which is depicted in Table 7.

Table 6. Smoothing constants ( $\alpha^{\prime}$ s) for the different variables.

\begin{tabular}{cc}
\hline Transportation Mode & $\boldsymbol{\alpha} \%$ \\
\hline Passenger cars & 1.2359 \\
Light trucks & 1.2195 \\
Bus & 0.8210 \\
Single-unit trucks & 1.1328 \\
\hline
\end{tabular}

Table 7. The Projection Error \% for the Different Variables.

\begin{tabular}{cc}
\hline Transportation Mode & Error\% \\
\hline Passenger cars & 2.39 \\
Light trucks & 5.04 \\
Bus & 7.73 \\
Single-unit trucks & 4.95 \\
GHG error & 1.94 \\
\hline
\end{tabular}

A summary of GHG emissions predictions has been made using the DES technique as shown in Figure 2. It has been predicted that by the year 2060, GHG emissions could rise to a figure around 2,957,400 K Metric Tons (Scenario 1). This increase is expected due to the increased modes of 
transportation. According to the Union of Concerned Scientist nationwide [69], GHG emissions for battery electric vehicles, the plug-in hybrids and gasoline vehicles are 144, 204 and 381 as depicted in Table 8. These figures are measured in terms of grams of $\mathrm{CO}_{2}$ per mile. Based on this data, Table 9 presents five possible scenarios that could result from shifting from one type of vehicles to another as described below:

- Gasoline-Plug-in vehicles-This would lead to about $46.5 \%$ reduction of national $\mathrm{CO}_{2}$ emissions (Scenario 2).

- Gasoline-battery electric vehicles-This would result in $62.2 \%$ decrease in $\mathrm{CO}_{2}$ emissions (Scenario 3).

- Use of $50 \%$ of battery electric and $50 \%$ of plug-in electric hybrid vehicles- $\mathrm{CO}_{2}$ emissions would reduce by $54.3 \%$ (Scenario 4 )

- $25 \%$ plug-in electric, $50 \%$ gasoline, $25 \%$ battery vehicles-This would result in $27.16 \%$ reduction of $27.16 \%$ (Scenario 5)

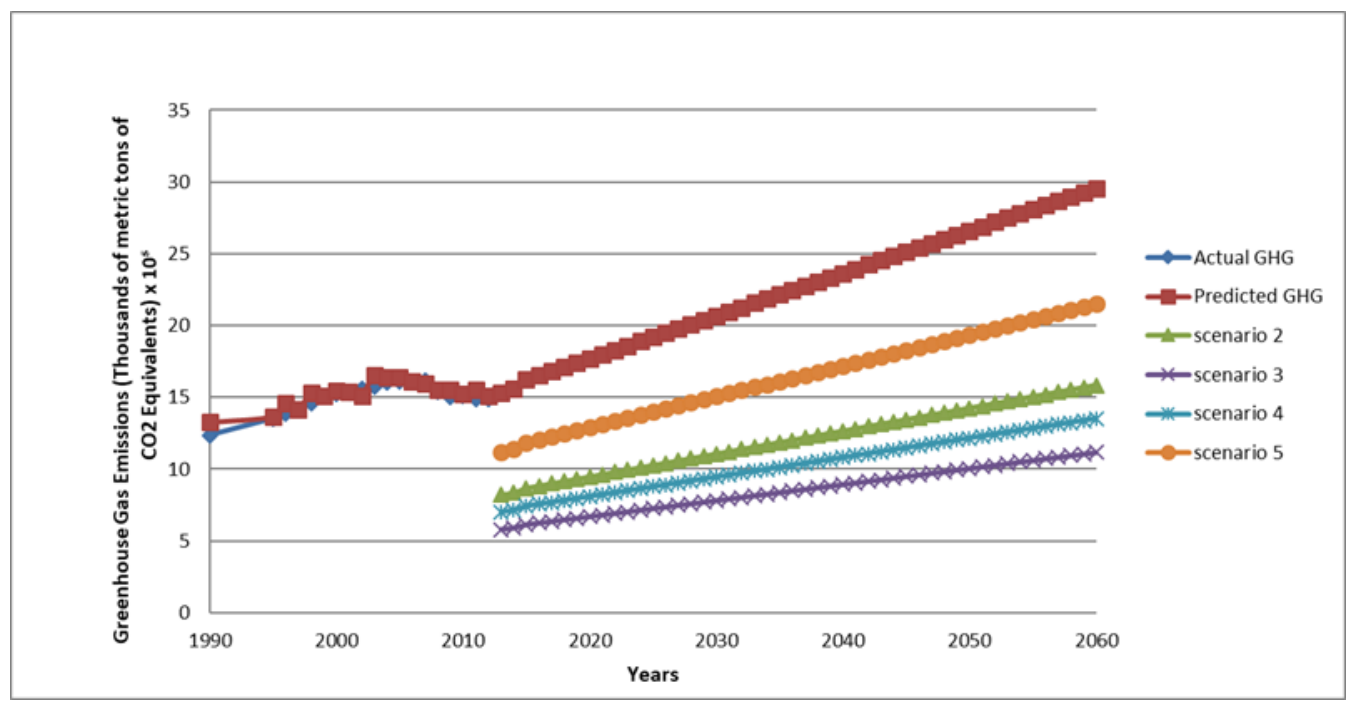

Figure 2. Actual Versus Predicted values of GHG Emissions for Five Scenarios.

Table 8. Average Emissions Nationwide [69].

\begin{tabular}{cc}
\hline Type of Vehicles & GHG Emission (Grams of $\mathbf{C O}_{\mathbf{2}}$ Equivalents per Mile) \\
\hline Gasoline vehicles & 381 \\
plug-in electric hybrids & 204 \\
battery electric vehicles & 144 \\
\hline
\end{tabular}

Table 9. The Reduction Value in GHG Emissions for Five Scenarios.

\begin{tabular}{ccccc}
\hline $\begin{array}{c}\text { Scenario } \\
\text { No. }\end{array}$ & $\begin{array}{c}\text { Gasoline } \\
\text { Vehicles \% }\end{array}$ & $\begin{array}{c}\text { Plug-in Electric } \\
\text { Hybrids (\%) }\end{array}$ & $\begin{array}{c}\text { Battery Electric } \\
\text { Vehicles (\%) }\end{array}$ & GHG Emission \\
\hline 1 & 100 & & & $\begin{array}{c}2,957,400 \mathrm{~K} \text { metric tons of } \mathrm{CO}_{2} \\
\text { Equivalents before } 2060\end{array}$ \\
2 & & 100 & 100 & $46.5 \%$ decrease in $\mathrm{CO}_{2}$ emissions \\
3 & & 50 & 50 & $62.2 \%$ decrease in $\mathrm{CO}_{2}$ production \\
4 & & 25 & 25 & $54.3 \%$ reduction in $\mathrm{CO}_{2}$ emissions \\
5 & 50 & $27.16 \%$ reduction in $\mathrm{CO}_{2}$ emissions \\
\hline
\end{tabular}




\section{Conclusions}

GHG emissions from the road transport sector pose a significant challenge. To cut these emissions, planners and decision makers need to formulate appropriate policies and strategies to reduce emissions from the transport sector.

At present, models that forecast GHG emissions have some constraints. In particular, the unavailability of detailed data (e.g., fuel consumption per vehicle, average annual distance travelled) poses a constraint to the development of the forecasting tool. Further, the models are complicated with numerous equations to satisfy many assumptions. Also, the methodology and assumptions made are sometimes too rigid, which makes such models and equations difficult to be used in practice [9]. By use of the multivariate linear regression model and double exponential smoothing analysis, this paper was able to examine GHG emissions factors which are associated with the road transportation sector. It made use of data collected in a span of 20 years (1990-2012) in the North America region. From the six modes of transportation, the VKM to NTV ratios were identified. The results indicate that the VKM to NTV ratio for the different transportation modes has a significant effect on GHG emissions, with the coefficient of determination adjusted $R^{2}$ and $R^{2}$ values of $89.46 \%$ and $91.8 \%$, respectively. The model has $1.48 \%$ error which is associated with the difference between the actual value and the value which had been predicted. It is found that the most crucial regression model variable is the use of a personal vehicle.

This study made use of a DES model in order to carry out predictions of variables which affect the emission of GHG. This gave a $1.94 \%$ error between the real and the predicted value. From these results, it is predicted that by 2060 , the emission of $\mathrm{CO}_{2}$ will rise to a figure around 2,957,400 K metric tons. This will happen if we continue using gasoline vehicle types only. A switch to battery electric would lead to a potential $62.2 \%$ decrease in emission of $\mathrm{CO}_{2}$. If we shift from $50 \%$ use gasoline vehicles and $25 \%$ use of plug-in vehicles as well as $25 \%$ of battery vehicles, this will yield a decrease of $\mathrm{CO}_{2}$ emission to $27.16 \%$. Use of both battery electric and plug-in vehicles on a $50 \%$ basis will result in $54.3 \%$ reduction of $\mathrm{CO}_{2}$ emissions. In the present study, the data set from one region (North America region) was used to test the model. Data sets from other regions or countries may be used in the future to test the robustness of the proposed method and reduce any geographical bias. Because the model was based on the results of historical data, it may not include new fuel-efficient technologies or processes that may evolve in the future. This means the model may need to be re-tested with newer sets of data which could further improve the model. Having said that, the generality of the approach should be applicable in the forecast of GHG emissions.

Many countries are aiming to reduce fuel/energy consumption and tailpipe GHG emissions of vehicles as road vehicles are a noticeable source of GHG emissions. For example, the European Commission set out a $60 \%$ reduction of transport emissions from 1990 levels by 2050. The GHG emissions forecasting tool as developed in this study may be used by planners and policymakers to estimate $\mathrm{CO}_{2}$ emissions resulting from different modes of road transport and the vehicle kilometers travelled. Further, the estimation of $\mathrm{CO}_{2}$ emissions can assist decisionmakers in developing a variety of policies or action plans to reduce the GHG emissions from the road transport sectors. For example, strict registration policies to promote the use of newer fuel-efficient vehicles, providing subsidies for fuel-efficient vehicles or implementing additional levies for older and polluting road vehicles could be implemented. This may help to reduce the greenhouse effect. In the future, researchers should conduct more analysis which is more detailed occurring at a disaggregated level and involving different and various transportation modes. While carrying out this study, a number of suggestions arose for further work on the topic of modelling GHG emissions from the transportation systems. First, an analysis which is more detailed occurring at a disaggregated level and involving different and various transportation modes including freights in fuel efficiencies needs to be conducted. Second, a more thorough analysis of the emissions factors for different kinds of travel and weekday-to-annual expansion factors may be insightful in terms of evaluation of GHG emissions in a community. Furthermore, it is recommended the five different scenarios as examined in this study are evaluated from a cost and economic point of 
view. Thirdly, more variables could be considered, such as the age of vehicles and new technology class of vehicles, that have a much lower carbon footprint as compared to older vehicles.

Author Contributions: This article is a joint work of the four authors. R.A, Y.A.N, A.K and N.S. R.A. conceptualization, collected the data, wrote the original draft and prepared the table. Y.A.N. analyzed the data and prepared figures. A.K. and N.S. reviewed the manuscript. All authors have read and agreed to the published version of the manuscript.

Funding: This research received no external funding.

Acknowledgments: The authors would like to thank the Australia Government Research Training Program (RTP) scholarship which has enabled us to conduct this research project.

Conflicts of Interest: The authors declare no conflict of interest.

\section{References}

1. Pauzi, H.M.; Abdullah, L. Performance Comparison of Two Fuzzy Based Models in Predicting Carbon Dioxide Emissions. In Proceedings of the First International Conference on Advanced Data and Information Engineering (DaEng-2013), Kuala Lumpur, Malaysia, 16-18 December 2013; Herawan, T., Deris, M.M., Abawajy, J., Eds.; Springer: Singapore, 2014; pp. 203-211. [CrossRef]

2. JAMA. Reducing $\mathrm{CO}_{2}$ Emissions in the Global Road Transport Sector; Japan Automobile Manufacturers Association Inc.: Tokyo, Japan, 2008.

3. OECD, ITF. Reducing Transport Greenhouse Gas Emissions Trends \& Data; OECD: Leipzig, Germany, 1 December 2010; p. 92. Available online: https://www.itf-oecd.org/sites/default/files/docs/10ghgtrends.pdf (accessed on 16 August 2019).

4. European Commission. Reducing Emissions from Transport. Available online: https://ec.europa.eu/clima/ policies/transport/vehicles_en (accessed on 15 March 2019).

5. Rentziou, A.; Gkritza, K.; Souleyrette, R.R. VMT, energy consumption, and GHG emissions forecasting for passenger transportation. Transp. Res. Part A Policy Pr. 2012, 46, 487-500. [CrossRef]

6. te Loo, R. A Methodology for Calculating $\mathrm{CO}_{2}$ Emissions from Transport and an Evaluation of the Impact of European Union Emission Regulations. Master's Thesis, Eindhoven University of Technology, Eindhoven, The Netherlands, August 2009.

7. Pokrovsky, O.M.; Kwok, R.H.F.; Ng, C.N. Fuzzy logic approach for description of meteorological impacts on urban air pollution species: A Hong Kong case study. Comput. Geosci. 2002, 28, 119-127. [CrossRef]

8. Choi, C.S.; Abdullah, L. Prediction of Carbon Dioxide Emissions Using Two Linear Regression-based Models: A Comparative Analysis. J. Appl. Eng. 2016, 4, 305-312.

9. OECD. Strategies to Reduce Greenhouse Gas Emissions from Road Transport; OECD Publishing: Paris, France, 1 January 2002. [CrossRef]

10. Can, S.D.L.R.D.; Khandekar, A.; Abhyankar, N.; Phadke, A.; Khanna, N.Z.; Fridley, D.; Zhou, N. Modeling India's energy future using a bottom-up approach. Appl. Energy 2019, 238, 1108-1125. [CrossRef]

11. Binh, N.T.; Tuan, V.A. Greenhouse Gas Emission from Freight Transport-Accounting for the Rice Supply Chain in Vietnam. Procedia CIRP 2016, 40, 46-49. [CrossRef]

12. Saboori, B.; Sapri, M.; Bin Baba, M. Economic growth, energy consumption and $\mathrm{CO}_{2}$ emissions in OECD (Organization for Economic Co-operation and Development)'s transport sector: A fully modified bi-directional relationship approach. Energy 2014, 66, 150-161. [CrossRef]

13. Lu, I.J.; Lewis, C.; Lin, S.J. The forecast of motor vehicle, energy demand and $\mathrm{CO}_{2}$ emission from Taiwan's road transportation sector. Energy Policy 2009, 37, 2952-2961. [CrossRef]

14. Meyer, I.; Leimbach, M.; Jaeger, C.C. International passenger transport and climate change: A sector analysis in car demand and associated emissions from 2000 to 2050. Energy Policy 2007, 35, 6332-6345. [CrossRef]

15. Tokunaga, K.; Konan, D.E. Home grown or imported? Biofuels life cycle GHG emissions in electricity generation and transportation. Appl. Energy 2014, 125, 123-131. [CrossRef]

16. Konur, D. Carbon constrained integrated inventory control and truckload transportation with heterogeneous freight trucks. Int. J. Prod. Econ. 2014, 153, 268-279. [CrossRef]

17. Tolón-Becerra, A.; Pérez-Martínez, P.J.; Lastra-Bravo, X.; Otero-Pastor, I. A methodology for territorial distribution of $\mathrm{CO}_{2}$ emission reductions in transport sector. Int. J. Energy Res. 2011, 36, 1298-1313. [CrossRef] 
18. Bekhet, H.; Yasmin, T. Disclosing the relationship among $\mathrm{CO}_{2}$ emissions, energy consumption, economic growth and bilateral trade between Singapore and Malaysia: An econometric analysis. Int. J. Energy Environ. Eng. 2013, 7, 2529-2534.

19. Bekhet, H.A.; Yusop, N.Y.M. Assessing the Relationship between Oil Prices, Energy Consumption and Macroeconomic Performance in Malaysia: Co-integration and Vector Error Correction Model (VECM) Approach. Int. Bus. Res. 2009, 2, 152. [CrossRef]

20. Ang, J.B. Economic development, pollutant emissions and energy consumption in Malaysia. J. Policy Model. 2008, 30, 271-278. [CrossRef]

21. Ediger, V.Ş.; Akar, S. ARIMA forecasting of primary energy demand by fuel in Turkey. Energy Policy 2007, 35, 1701-1708. [CrossRef]

22. Wang, S.S.; Zhou, D.Q.; Zhou, P.; Wang, Q.W. $\mathrm{CO}_{2}$ emissions, energy consumption and economic growth in China: A panel data analysis. Energy Policy 2011, 39, 4870-4875. [CrossRef]

23. Begum, R.A.; Sohag, K.; Abdullah, S.M.S.; Jaafar, M. $\mathrm{CO}_{2}$ emissions, energy consumption, economic and population growth in Malaysia. Renew. Sustain. Energy Rev. 2015, 41, 594-601. [CrossRef]

24. Ivy-Yap, L.L.; Bekhet, H.A. Examining the feedback response of residential electricity consumption towards changes in its determinants: Evidence from Malaysia. Int. J. Energy Econ. Policy 2015, 5, 772-781.

25. Talbi, B. $\mathrm{CO}_{2}$ emissions reduction in road transport sector in Tunisia. Renew. Sustain. Energy Rev. 2017, 69, 232-238. [CrossRef]

26. Magazzino, C.; Mele, M.; Schneider, N. The relationship between municipal solid waste and greenhouse gas emissions: Evidence from Switzerland. Waste Manag. 2020, 113, 508-520. [CrossRef]

27. Timilsina, G.R.; Shrestha, A. Transport sector $\mathrm{CO}_{2}$ emissions growth in Asia: Underlying factors and policy options. Energy Policy 2009, 37, 4523-4539. [CrossRef]

28. Chandran, V.G.R.; Tang, C.F. The impacts of transport energy consumption, foreign direct investment and income on $\mathrm{CO}_{2}$ emissions in ASEAN-5 economies. Renew. Sustain. Energy Rev. 2013, 24, 445-453. [CrossRef]

29. Andreoni, V.; Galmarini, S. European $\mathrm{CO}_{2}$ emission trends: A decomposition analysis for water and aviation transport sectors. Energy 2012, 45, 595-602. [CrossRef]

30. Lakshmanan, T.R.; Han, X. Factors underlying transportation $\mathrm{CO}_{2}$ emissions in the U.S.A.: A decomposition analysis. Transp. Res. Part D Transp. Environ. 1997, 2,1-15. [CrossRef]

31. Li, W.; Li, H.; Zhang, H.; Sun, S. The Analysis of $\mathrm{CO}_{2}$ Emissions and Reduction Potential in China's Transport Sector. Math. Probl. Eng. 2016, 2016, 1-12. [CrossRef]

32. Fan, F.; Lei, Y. Decomposition analysis of energy-related carbon emissions from the transportation sector in Beijing. Transp. Res. Part D Transp. Environ. 2016, 42, 135-145. [CrossRef]

33. Sadorsky, P. The effect of urbanization on $\mathrm{CO}_{2}$ emissions in emerging economies. Energy Econ. 2014, 41, 147-153. [CrossRef]

34. Shu, Y.; Lam, N.S.N. Spatial disaggregation of carbon dioxide emissions from road traffic based on multiple linear regression model. Atmos. Environ. 2011, 45, 634-640. [CrossRef]

35. Alhindawi, R.; Abu Nahleh, Y.; Kumar, A.; Shiwakoti, N. A multivariate regression model for road sector greenhouse gas emission. In Proceedings of the ARRB 2016: Linking People, Places and Opportunities, Melbourne, Australia, 16-18 November 2016; pp. 1-10.

36. Alhindawi, R.; Abu Nahleh, Y.; Kumar, A.; Shiwakoti, N. Application of a Adaptive Neuro-Fuzzy Technique for Projection of the Greenhouse Gas Emissions from Road Transportation. Sustainability 2019, 11, 6346. [CrossRef]

37. Xu, S.-C.; He, Z.-X.; Long, R.-Y. Factors that influence carbon emissions due to energy consumption in China: Decomposition analysis using LMDI. Appl. Energy 2014, 127, 182-193. [CrossRef]

38. Friedrich, E.; Trois, C. Current and future greenhouse gas (GHG) emissions from the management of municipal solid waste in the eThekwini Municipality-South Africa. J. Clean. Prod. 2016, 112, 4071-4083. [CrossRef]

39. Alshehry, A.S.; Belloumi, M. Study of the environmental Kuznets curve for transport carbon dioxide emissions in Saudi Arabia. Renew. Sustain. Energy Rev. 2017, 75, 1339-1347. [CrossRef]

40. Lin, B.; Benjamin, N.I. Influencing factors on carbon emissions in China transport industry. A new evidence from quantile regression analysis. J. Clean. Prod. 2017, 150, 175-187. [CrossRef] 
41. Danish; Baloch, M.A.; Suad, S. Modeling the impact of transport energy consumption on $\mathrm{CO}_{2}$ emission in Pakistan: Evidence from ARDL approach. Environ. Sci. Pollut. Res. 2018, 25, 9461-9473. [CrossRef] [PubMed]

42. van der Zwaan, B.; Keppo, I.; Johnsson, F. How to decarbonize the transport sector? Energy Policy 2013, 61, 562-573. [CrossRef]

43. Bellasio, R.; Bianconi, R.; Corda, G.; Cucca, P. Emission inventory for the road transport sector in Sardinia (Italy). Atmos. Environ. 2007, 41, 677-691. [CrossRef]

44. He, L.-Y.; Chen, Y. Thou shalt drive electric and hybrid vehicles: Scenario analysis on energy saving and emission mitigation for road transportation sector in China. Transp. Policy 2013, 25, 30-40. [CrossRef]

45. Dallmann, T.R.; Kirchstetter, T.W.; DeMartini, S.J.; Harley, R.A. Quantifying On-Road Emissions from Gasoline-Powered Motor Vehicles: Accounting for the Presence of Medium- and Heavy-Duty Diesel Trucks. Environ. Sci. Technol. 2013, 47, 13873-13881. [CrossRef]

46. Sider, T.; Alam, A.; Zukari, M.; Dugum, H.; Goldstein, N.; Eluru, N.; Hatzopoulou, M. Land-use and socio-economics as determinants of traffic emissions and individual exposure to air pollution. J. Transp. Geogr. 2013, 33, 230-239. [CrossRef]

47. Paladugula, A.L.; Kholod, N.; Chaturvedi, V.; Ghosh, P.P.; Pal, S.; Clarke, L.; Evans, M.; Kyle, P.; Koti, P.N.; Parikh, K.; et al. A multi-model assessment of energy and emissions for India's transportation sector through 2050. Energy Policy 2018, 116, 10-18. [CrossRef]

48. Börjesson, M.; Ahlgren, E.O. Assessment of transport fuel taxation strategies through integration of road transport in an energy system model-the case of Sweden. Int. J. Energy Res. 2011, 36, 648-669. [CrossRef]

49. Bai, H.; Wei, J.-H. The $\mathrm{CO}_{2}$ mitigation options for the electric sector. A case study of Taiwan. Energy Policy 1996, 24, 221-228. [CrossRef]

50. Wang, C.; Larsson, M.; Ryman, C.; Grip, C.-E.; Wikström, J.-O.; Johnsson, A.; Engdahl, J. A model on $\mathrm{CO}_{2}$ emission reduction in integrated steelmaking by optimization methods. Int. J. Energy Res. 2008, 32, 1092-1106. [CrossRef]

51. Hashim, H.; Douglas, P.; Elkamel, A.A.; Croiset, E. Optimization Model for Energy Planning with $\mathrm{CO}_{2}$ Emission Considerations. Ind. Eng. Chem. Res. 2005, 44, 879-890. [CrossRef]

52. Tan, S.; Hashim, H.; Ho, W.; Lee, C. Optimal planning of waste-to-energy through mixed integer linear programming. Int. J. Environ. Ecol. Eng. 2013, 7, 372-379.

53. Güzel, T.D.; Alp, K. Modeling of greenhouse gas emissions from the transportation sector in Istanbul by 2050. Atmos. Pollut. Res. 2020. [CrossRef]

54. Choi, J.; Roberts, D.C.; Lee, E. Forecast of $\mathrm{CO}_{2}$ Emissions from the U.S. Transportation Sector: Estimation From a Double Exponential Smoothing Model. J. Transp. Res. Forum 2014, 63-81. [CrossRef]

55. Brown, R.G. Exponential smoothing for predicting demand. In Proceedings of the 10th National Meeting of the Operations Research Society of America, San Francisco, CA, USA, 14-15 November 1956.

56. Brown, R.G.; Meyer, R.F. The Fundamental Theorem of Exponential Smoothing. Oper. Res. 1961, 9, $673-685$. [CrossRef]

57. Goodman, M.L. A New Look at Higher-Order Exponential Smoothing for Forecasting. Oper. Res. 1974, 22, 880-888. [CrossRef]

58. Gardner, E.S. Exponential smoothing: The state of the art. J. Forecast. 1985, 4, 1-28. [CrossRef]

59. Gijbels, I.; Pope, A.; Wand, M.P. Understanding exponential smoothing via kernel regression. J. R. Stat. Soc. Ser. B Stat. Methodol. 1999, 61, 39-50. [CrossRef]

60. Oh, S.C.; Sohn, S.H.; Yeo, Y.-K.; Chang, K.S. A study on the prediction of ozone formation in air pollution. Korean J. Chem. Eng. 1999, 16, 144-149. [CrossRef]

61. Taylor, J.W. Short-term electricity demand forecasting using double seasonal exponential smoothing. J. Oper. Res. Soc. 2003, 54, 799-805. [CrossRef]

62. Xie, Z.-W.; Su, K.-Y. Improved Grey Model Base on Exponential Smoothing for River Water Pollution Prediction. In Proceedings of the 2010 4th International Conference on Bioinformatics and Biomedical Engineering, Chengdu, China, 18-20 June 2010; pp. 1-4.

63. Gupta, M.; Shum, L.V.; Bodanese, E.; Hailes, S. Design and evaluation of an adaptive sampling strategy for a wireless air pollution sensor network. In Proceedings of the 2011 IEEE 36th Conference on Local Computer Networks, Institute of Electrical and Electronics Engineers (IEEE), Bonn, Germany, 4-7 October 2011; pp. 1003-1010. 
64. Sullivan, W.G.; Claycombe, W.W. Fundamentals of Forecasting; Reston Pub. Co.: Reston, VA, USA, 1977.

65. Hyndman, R.J.; Koehler, A.; Ord, J.K.; Snyder, R.D.; Hyndman, R.J. Forecasting with Exponential Smoothing the State Space Approach; Springer: Dordrecht/Berlin, Germany, 2008.

66. Bureau of Infrastructure and Transport Research Economics. Road Vehiclekilometres Travelled: Estimation from State and Territory Fuel Sales. Available online: http://www.bitre.gov.au (accessed on 4 July 2019).

67. NATS. North America Transportation Statistics. Available online: http://nats.sct.gob.mx/language/en/ (accessed on 10 February 2019).

68. Rudy, K. Checking Assumptions about Residuals in Regression Analysis. Available online: http://blog.minitab.com/blog/the-statistics-game/checking-the-assumption-of-constant-variancein-regression-analyses (accessed on 10 June 2019).

69. Union of Concerned Scientists. How Clean Is Your Electric Vehicle? Available online: http://www.ucsusa. org/clean-vehicles/electric-vehicles/ev-emissions-tool\#.WhuXklWWaUk (accessed on 16 August 2019).

Publisher's Note: MDPI stays neutral with regard to jurisdictional claims in published maps and institutional affiliations.

(C) 2020 by the authors. Licensee MDPI, Basel, Switzerland. This article is an open access article distributed under the terms and conditions of the Creative Commons Attribution (CC BY) license (http://creativecommons.org/licenses/by/4.0/). 